\title{
Combination therapy with rituximab, low-dose cyclophosphamide, and prednisone for idiopathic membranous nephropathy: a case series
}

Frank B. Cortazar ${ }^{1 *}$, David E. Leaf ${ }^{2}$, Charles T. Owens ${ }^{3}$, Karen Laliberte' ${ }^{1}$, William F. Pendergraft $1 \mathrm{I}^{4}$ and John L. Niles ${ }^{1}$

\begin{abstract}
Background: Membranous nephropathy is a common cause of the nephrotic syndrome. Treatment with standard regimens fails to induce complete remission in most patients. We evaluated the efficacy of combination therapy with rituximab, low-dose, oral cyclophosphamide, and an accelerated prednisone taper (RCP) for the treatment of idiopathic membranous nephropathy.

Methods: We analyzed 15 consecutive patients with idiopathic membranous nephropathy treated with RCP at Massachusetts General Hospital. Seven patients (47\%) received RCP as initial therapy, and the other eight patients (53\%) received RCP for relapsing or refractory disease. All patients had at least 1 year of follow-up. The co-primary outcomes were attainment of partial and complete remission. Partial remission was defined as a urinary protein to creatinine ratio (UPCR) $<3 \mathrm{~g} / \mathrm{g}$ and a $50 \%$ reduction from baseline. Complete remission was defined as a UPCR $<0$. $3 \mathrm{~g} / \mathrm{g}$. Secondary outcomes were serious adverse events and the change in proteinuria, serum creatinine, serum albumin, cholesterol, triglycerides, and immunoglobulin G levels after 1 year of treatment.

Results: Over a median follow-up time of 37 (IQR, 34-44) months, 100\% of patients achieved partial remission and 93\% of patients achieved complete remission at a median time of 2 and 13 months, respectively. After 1 year of treatment, median (IQR) UPCR declined from $8.2(6.6-11.1)$ to $0.3(0.2-0.7) \mathrm{g} / \mathrm{g}(P<0.001)$. Three serious adverse events occurred over 51 patient years. No patients died or progressed to ESKD.

Conclusions: Treatment of idiopathic membranous nephropathy with RCP resulted in high rates of complete remission. Larger studies evaluating this regimen are warranted.
\end{abstract}

Keywords: Membranous nephropathy, Cyclophosphamide, Rituximab, Remission

\section{Background}

Membranous nephropathy (MN) is one of the most common causes of the nephrotic syndrome [1]. Approximately $75 \%$ of MN cases are idiopathic [2]. The course of idiopathic $\mathrm{MN}$ in patients not receiving immunosuppressive therapy is variable. Approximately $35 \%$ of patients achieve complete or partial spontaneous remission, while

\footnotetext{
* Correspondence: fcortazar@partners.org

'Vasculitis and Glomerulonephritis Center, Division of Nephrology,

Massachusetts General Hospital, 101 Merrimac St, Boston 02114, MA, USA

Full list of author information is available at the end of the article
}

$40 \%$ of patients ultimately progress to end-stage kidney disease (ESKD) over a 10 year period [3, 4]. Risk factors for progressive renal decline, and therefore treatment with immunosuppression, include persistent proteinuria of $>4 \mathrm{~g}$ per day despite treatment with an angiotensin converting enzyme inhibitor (ACE-I) or angiotensin receptor blocker (ARB) and/or abnormal or worsening estimated glomerular filtration rate (eGFR) attributed to $\mathrm{MN}[5]$.

When immunosuppressive therapy is indicated, current guidelines recommend the Ponticelli protocol, a 6-month course of alternating monthly oral cyclophosphamide and 
corticosteroids [6, 7]. Alternatively, a calcineurin inhibitor-based regimen with or without low-dose prednisone is recommended if there is a desire to avoid an alkylating agent [6]. Unfortunately, these regimens generally result in rates of complete remission of $<35 \%$ [7-10].

The M-type phospholipase A2 receptor (PLA2R), a transmembrane protein expressed on glomerular podocytes, has been demonstrated to be the target antigen in most cases of idiopathic MN [11]. This creates a paradigm whereby circulating autoantibodies to PLA2R form in situ immune complexes at the level of the podocyte, leading to the development of MN. The central mechanistic role for autoantibodies in MN has provided a rationale for B cell targeted therapy. However, monotherapy treatment with rituximab, a monoclonal anti- CD20 antibody, fails to induce complete remission in the vast majority of patients [12-14].

In an attempt to more effectively induce remission while allowing for a reduced exposure to high-dose glucocorticoids, the practice pattern in our group for the treatment of newly diagnosed, relapsing, and refractory idiopathic $\mathrm{MN}$ evolved to become a three drug regimen: rituximab dosed to maintain continuous $B$ cell depletion, a 2-month course of oral, low-dose, bridging cyclophosphamide, and an accelerated prednisone taper (RCP). Given that $\mathrm{MN}$ is an antibody mediated disease, the premise of this regimen is to target plasma cells with cyclophosphamide and glucocorticoids while concurrently depleting plasma cell precursors with rituximab. We present a retrospective analysis of the outcomes of 15 consecutive patients treated with this regimen.

\section{Methods}

\section{Patient selection}

Starting in July of 2009, combination therapy with rituximab, glucocorticoids, and cyclophosphamide became the preferred immunosuppressive regimen for patients presenting to the Massachusetts General Hospital Vasculitis and Glomerulonephritis Center with idiopathic MN. We performed a retrospective analysis of patients treated with this regimen who had biopsy-proven $\mathrm{MN}$ and met at least one of the following criteria: 1) persistent urinary protein to creatinine ratio (UPCR) $>4 \mathrm{~g} / \mathrm{g}$ for $>6$ months despite treatment with an ACE-I or ARB; 2) declining renal function, defined as a $30 \%$ rise in serum creatinine from baseline attributed to $\mathrm{MN}$; 3) debilitating or life threatening symptoms due to the nephrotic syndrome; 4) recurrence of a UPCR $>4 \mathrm{~g} / \mathrm{g}$ following remission after a prior immunosuppressive treatment; or 5) refractory disease, defined as failure of an alternative immunosuppressive regimen to induce a partial remission after at least 6 months of therapy. Patients were considered to have the nephrotic syndrome if they had a UPCR $>3.5 \mathrm{~g} / \mathrm{g}$, a serum albumin $<3 \mathrm{~g} / \mathrm{dL}$, and peripheral edema.
As part of routine care, all patients were evaluated for secondary causes of $\mathrm{MN}$ by age-appropriate cancer screening, assessment for occult malignancy as indicated based on history and physical examination, review of medications for potential drug culprits, screening for hepatitis $\mathrm{B}$ and $\mathrm{C}$ viruses, antinuclear antibody testing, and pursuing additional testing as deemed appropriate by the treating nephrologist. After retrospective chart review, patients were excluded from the analysis if they were found to have a malignancy, active hepatitis $\mathrm{B}$ or $\mathrm{C}$, lupus membranous, or exposure to a medication known to cause MN. All patients with at least 1 year of follow-up were included in the study. The study was approved by the Massachusetts General Hospital Institutional Review Board.

\section{Treatment regimen}

A summary of the treatment regimen is shown in Fig. 1. Cyclophosphamide was administered orally at $2.5 \mathrm{mg} / \mathrm{kg}$ daily for 1 week, then $1.5 \mathrm{mg} / \mathrm{kg}$ daily for 7 weeks. The dose of cyclophosphamide was adjusted for renal function as follows: $10 \%$ dose reduction if the eGFR was $60-90 \mathrm{ml} /$ $\min / 1.73 \mathrm{~m}^{2}, 25 \%$ if the eGFR was $45-59 \mathrm{ml} / \mathrm{min} /$ $1.73 \mathrm{~m}^{2}, 33 \%$ if the eGFR was $30-44 \mathrm{ml} / \mathrm{min} / 1.73 \mathrm{~m}^{2}$, and $40 \%$ if the eGFR was $15-29 \mathrm{ml} / \mathrm{min} / 1.73 \mathrm{~m}^{2}$. GFR was estimated using the Chronic Kidney Disease Epidemiology Collaboration (CKD-EPI) equation [15]. Concurrently with the start of cyclophosphamide, patients were initiated on rituximab with two $1000 \mathrm{mg}$ intravenous doses separated by approximately 2 weeks. Thereafter, patients received rituximab $1000 \mathrm{mg}$ IV every 4 months for 2 years with the aim of maintaining continuous $\mathrm{B}$ cell depletion. The rituximab dosing interval was based on data indicating that B cell reconstitution commences 16 weeks after rituximab administration in a significant subset of

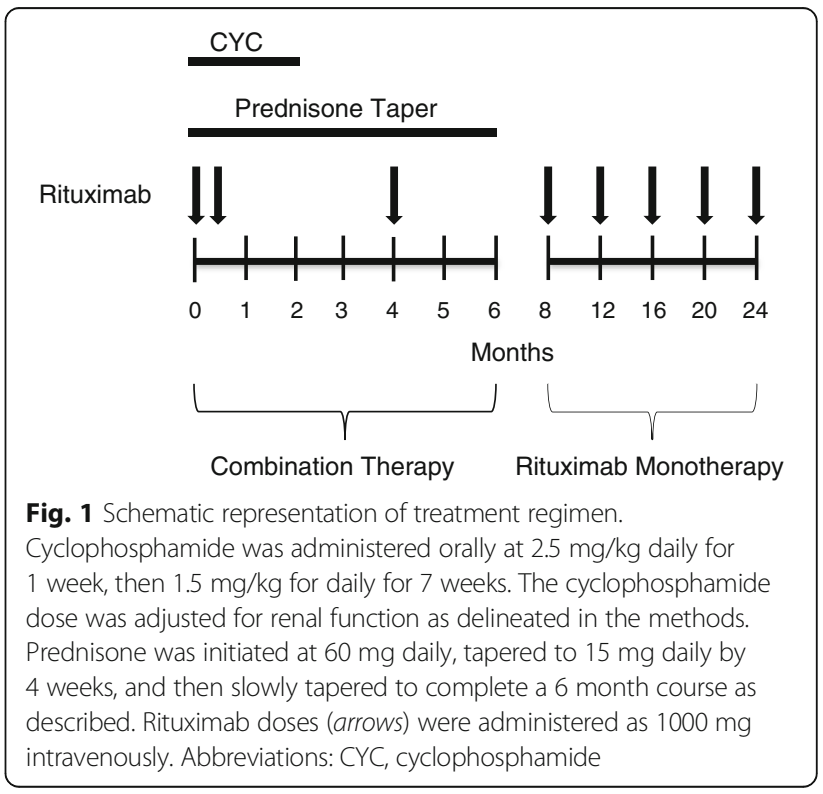


patients [16]. To ensure continuous B cell depletion was achieved, peripheral blood was sent for flow cytometry analysis immediately prior to each rituximab dose. Prednisone was tapered as follows: $60 \mathrm{mg}$ daily for 1 week, $40 \mathrm{mg}$ daily for 1 week, $30 \mathrm{mg}$ daily for 1 week, $20 \mathrm{mg}$ daily for 1 week, and then a slow taper to complete a 6 month course. Minor modifications of the treatment regimen were permitted at the discretion of the treating physician.

Patients were typically seen in clinic at presentation, 1 week (first rituximab dose), 3 weeks (second rituximab dose), 2 months, 4 months, and then every 4 months during the active treatment phase. Following treatment, patients were seen every 4 to 6 months for monitoring. The following labs were checked at each visit: complete blood count $(\mathrm{CBC})$, comprehensive metabolic panel, spot urine total protein, and spot urine creatinine. A CBC was checked every 2-3 weeks while patients were on cyclophosphamide to monitor for leukopenia. Lipids were checked every 4 months. Peripheral blood was sent for flow cytometry (to monitor for B cell depletion) and serum immunoglobulins prior to each rituximab infusion. Some patients were tested for antibodies to the M-type phospholipase A2 receptor (PLA2R). Testing for antibodies to PLA2R was performed on peripheral blood via enzymelinked immunosorbent assay (Euroimmun, Lubeck, Germany) or from staining deposits on kidney biopsies for PLA2R via immunofluorescence.

\section{Primary outcomes}

The primary outcomes were attainment of partial and complete remission. Partial remission was defined as a $\mathrm{UPCR}<3.0 \mathrm{~g} / \mathrm{g}$ and $\mathrm{a} \geq 50 \%$ reduction in the UPCR from baseline. Complete remission was defined as a UPCR $<$ $0.3 \mathrm{~g} / \mathrm{g}$. Relapse after complete or partial remission was defined as a UPCR $>3 \mathrm{~g} / \mathrm{g}$. All UPCRs were determined with a spot collection.

\section{Secondary outcomes}

Secondary outcomes included the change in proteinuria, serum creatinine, serum albumin, total cholesterol, triglycerides, and immunoglobulin $G$ levels from baseline to 1 year after treatment.

\section{Serious adverse events}

At each visit, patients were asked about any interval infections, hospitalizations, or other complications. All reported adverse events were recorded in our electronic treatment flowsheets. To ensure accuracy, we report only serious adverse events, defined as those that were life threatening or required hospitalization.

\section{Statistical analysis}

Analyses were carried out using STATA version 14 (College Station, Texas). Baseline characteristics are presented as percentages or medians and interquartile ranges (IQRs), and were compared using the Wilcoxon rank-sum test or Fisher's exact test, as appropriate. Longitudinal differences in clinical parameters from baseline to 1 year after initiation of treatment were analyzed with the Wilcoxon signed-rank test.

The Kaplan-Meier method was used to examine the time to achieving a complete or partial remission. Time to event was the time from initiation of treatment to the attainment of complete or partial remission. The analysis was stratified by disease status (initial presentation versus relapsing/refractory disease). Differences between curves were assessed using the log-rank test and proportionalhazards model. All comparisons are two-tailed, with $P<0.05$ considered significant.

\section{Results}

\section{Baseline characteristics}

In September of 2015, 15 consecutive patients with idiopathic MN treated with rituximab, cyclophosphamide, and prednisone (RCP) had at least 1 year of follow-up. Seven patients $(47 \%)$ received RCP as initial therapy. The remaining eight patients (53\%) were referrals from other physicians who had been previously treated for idiopathic $\mathrm{MN}$ and had relapsing or refractory disease. Baseline characteristics overall and stratified by treatment status are presented in Table 1 .

The median age at presentation was 62 years (IQR, $45-67$ years) and $53 \%$ of patients were female. The study population consisted of 13 Caucasian patients, 1 black patient, and 1 Hispanic patient. Baseline autoantibodies to PLA2R were present in 4 of 5 patients with available data. The most common treatment indication for patients receiving $\mathrm{RCP}$ as initial therapy was debilitating symptoms of the nephrotic syndrome. Patients receiving RCP as second-line therapy were most commonly treated for a disease relapse (UPCR $>4 \mathrm{~g} / \mathrm{g}$ ) occurring after prior disease remission induced by immunosuppression and failure of 6 months of an ACE-I or ARB to result in a reduction of UPCR to $<4 \mathrm{~g} / \mathrm{g}$. All patients receiving RCP as secondline therapy and 1 patient receiving $\mathrm{RCP}$ as initial therapy met more than 1 treatment indication.

The median UPCR was 8.2 (IQR, 6.8-11.4) g/g and was similar in patients receiving RCP as initial versus second-line therapy. The majority of patients in both treatment groups had the nephrotic syndrome. Baseline serum creatinine was higher in patients receiving RCP as second-line therapy compared to initial therapy (median [IQR], $1.3[1.2-2.1]$ versus $0.8[0.5-0.09] \mathrm{mg} / \mathrm{dl}, P=0.011)$. Three patients had an eGFR $30-60 \mathrm{ml} / \mathrm{min} / 1.73 \mathrm{~m}^{2}$, and two patients had an eGFR $<30 \mathrm{ml} / \mathrm{min} / 1.73 \mathrm{~m}^{2}$.

Of the 8 patients who received prior treatment, 4 (50\%) had been treated with 2 different treatment regimens. The 8 patients with relapsing or refractory disease 
Table 1 Baseline characteristics

\begin{tabular}{|c|c|c|c|c|}
\hline Variable & Overall $(n=15)$ & Initial therapy $(n=7)$ & Second-line therapy $(n=8)$ & $P$ value \\
\hline Age (years) & $62(45-67)$ & $52(39-62)$ & $64(57-67)$ & 0.12 \\
\hline Female & $8(53)$ & $5(71)$ & $3(38)$ & 0.32 \\
\hline Systolic BP (mmHg) & $140(124-148)$ & $124(114-140)$ & $147(135-164)$ & 0.037 \\
\hline Diastolic BP (mmHg) & $82(72-86)$ & $80(67-86)$ & $83(79-89)$ & 0.29 \\
\hline Serum Creatinine (mg/dL) & $1.2(0.8-1.5)$ & $0.8(0.5-0.9)$ & $1.3(1.2-2.1)$ & 0.011 \\
\hline $\operatorname{eGFR}\left(\mathrm{ml} / \mathrm{min} / 1.73 \mathrm{~m}^{2}\right)$ & $65(40-100)$ & $100(62-123)$ & $56(29-66)$ & 0.024 \\
\hline eGFR Group & & & & 0.45 \\
\hline$>60 \mathrm{ml} / \mathrm{min} / 1.73 \mathrm{~m}^{2}$ & $10(67)$ & $6(86)$ & $4(50)$ & \\
\hline $30-60 \mathrm{ml} / \mathrm{min} / 1.73 \mathrm{~m}^{2}$ & $3(20)$ & $1(14)$ & $2(25)$ & \\
\hline$<30 \mathrm{ml} / \mathrm{min} / 1.73 \mathrm{~m}^{2}$ & $2(13)$ & $0(0)$ & $2(25)$ & \\
\hline UPCR (g/g) & $8.2(6.8-11.4)$ & $6.9(5.2-10.2)$ & $10.1(8.0-11.7)$ & 0.15 \\
\hline UPCR group & & & & 0.41 \\
\hline$<4^{a}$ & $1(7)$ & $1(14)$ & $0(0)$ & \\
\hline $4-8$ & $5(33)$ & $3(43)$ & $2(25)$ & \\
\hline$>8$ & $9(60)$ & $3(43)$ & $6(75)$ & \\
\hline Nephrotic Syndrome ${ }^{b}$ & $13(87)$ & $7(100)$ & $6(75)$ & 0.47 \\
\hline Albumin (g/dL) & $2.7(2.5-2.8)$ & $2.7(2.5-2.8)$ & $2.6(2.4-3.1)$ & 0.86 \\
\hline Total Cholesterol $(\mathrm{mg} / \mathrm{dL})^{c}$ & $350(252-371)$ & $341(252-367)$ & $371(249-438)$ & 0.34 \\
\hline Triglycerides $(\mathrm{mg} / \mathrm{dL})^{c}$ & $172(122-270)$ & $134(77-192)$ & $177(155-546)$ & 0.14 \\
\hline Time Since Biopsy Diagnosis (months) & $9(3-24)$ & $3(0.5-4)$ & $23(16-60)$ & 0.011 \\
\hline On ACE-I or ARB & $13(87)$ & $5(71)$ & $8(100)$ & 0.20 \\
\hline On Statin & $8(53)$ & $2(29)$ & $6(75)$ & 0.13 \\
\hline \multicolumn{5}{|l|}{ Treatment Indications } \\
\hline Failure of $A C E-I$ or $A R B^{d}$ & $8(53)$ & $2(29)$ & $6(75)$ & 0.13 \\
\hline Declining Renal Function & $5(33)$ & $1(14)$ & $4(50)$ & 0.30 \\
\hline Debilitating Symptoms from nephrotic syndrome & $10(67)$ & $5(71)$ & $5(63)$ & 0.99 \\
\hline Relapsing Disease & $6(38)$ & NA & $6(75)$ & NA \\
\hline Refractory Disease & $3(19)$ & NA & $3(38)$ & NA \\
\hline
\end{tabular}

Data are presented as median (interquartile range) and $n$ (\%)

Abbreviations: $A C E-I$ angiotensin converting enzyme, $A R B$ angiotensin receptor blocker, BP blood pressure, eGFR estimated glomerular filtration rate, UPCR urinary protein: creatinine ratio

${ }^{\text {a }}$ The patient with a UPCR $<4 \mathrm{~g} / \mathrm{g}$ had decompensated nephrotic syndrome with refractory edema and an albumin nadir of $1.1 \mathrm{~g} / \mathrm{dL}$

${ }^{\mathrm{b}}$ Nephrotic syndrome was defined as urinary protein: creatinine ratio $>3.5 \mathrm{~g} / \mathrm{g}$, serum albumin $<3 \mathrm{~g} / \mathrm{dL}$, and peripheral edema

'One patient in the second-line therapy group did not have baseline cholesterol or triglycerides

${ }^{d}$ Failure of ACE-I or ARB was defined as a persistent UPCR $>4 \mathrm{~g} / \mathrm{g}$ despite at least 6 months of therapy

were exposed to 12 different treatment regimens. In combination with prednisone, 3 patients were treated with cyclophosphamide, 2 with mycophenolate mofetil, 3 with cyclosporine, and 1 with tacrolimus. Three patients received prednisone monotherapy.

The five patients treated with RCP for disease relapse had a median immunosuppression-free interval of 18 months (IQR, 12 to 84 months). In all cases, the UPCR at initiation of RCP was greater than the UPCR 6 months prior (median difference $1.5 \mathrm{~g} / \mathrm{g}$ [IQR, 0.6 to $4.1 \mathrm{~g} / \mathrm{g}])$. The characteristics of patients treated for refractory disease are presented in Table 2 .

\section{Primary outcomes}

Median follow-up time was 37 (IQR, 34-44) months. All patients achieved partial remission by 1 year. Median time to achievement of partial remission was 2 (IQR, 1-7) months (Fig. 2a). There was a trend toward faster induction of partial remission in patients receiving RCP as initial treatment versus second-line therapy (HR 3.2; 95\% CI 0.9-10.6; $P=0.06$, Fig. 2b).

Fourteen patients (93\%) achieved complete remission at a median time of 13 (IQR, 12-17) months (Fig. 2c). All 14 patients who achieved complete remission had a subsequent confirmatory UPCR $<0.3 \mathrm{~g} / \mathrm{g}$ 
Table $\mathbf{2}$ Characteristics of patients with refractory disease

\begin{tabular}{llllc}
\hline Patient & Regimen & $\begin{array}{l}\text { Duration of } \\
\text { therapy (mos) }\end{array}$ & $\begin{array}{l}\text { UPCR 6 months } \\
\text { before RCP }\end{array}$ & $\begin{array}{l}\text { UPCR at RCP } \\
\text { initiation }\end{array}$ \\
\hline 1 & MMF \& Pred & 12 & 5.2 & 10.7 \\
2 & CSA \& Pred & 18 & NA & 11.9 \\
3 & CSA \& Pred & 6 & 6.8 & 16.7 \\
\hline
\end{tabular}

Abbreviations: CSA cyclosporine, MMF mycophenolate mofetil, mos months, NA not available, Pred prednisone, UPCR urinary protein: creatinine ratio, $R C P$ rituximab, cyclophosphamide, prednisone

(Additional file 1: Figure S1). The one patient who failed to achieve complete remission had advanced CKD attributed to $\mathrm{MN}$ with an eGFR of $18 \mathrm{ml} / \mathrm{min} / 1.73 \mathrm{~m}^{2}$ at initiation of RCP. Like with attainment of partial remission, there was a trend to more rapid induction of complete remission in patients receiving $\mathrm{RCP}$ as initial therapy (HR 2.7; 95\% CI 0.8-8.5; $P=0.10$, Fig. 2d). Antibodies to PLA2R became undetectable after treatment with RCP in the 3 patients with documented circulating antibodies at baseline

Additional treatment was required in 2 patients who had persistent nephrotic-range proteinuria at their 4 month follow-up visit. Both of these patients received an additional 2 month course of cyclophosphamide at $1 \mathrm{mg} / \mathrm{kg}$ and subsequently achieved complete remission. One patient relapsed 9 months after partial remission while B cells remained depleted, but achieved complete remission after treatment with an additional 1 month of cyclophosphamide at $1.5 \mathrm{mg} / \mathrm{kg}$.

At last follow-up the full 2-year regimen was completed by 14 patients, 8 of whom had relapsing or refractory disease. Following completion of the 2-year regimen, one relapse occurred over 20 patient-years of treatment-free follow-up (median treatment-free follow-up, 13.7 [IQR, 10 to 19] months). The relapse occurred 4.8 years after the patient's last rituximab dose. At the time of relapse, B cells had reconstituted and accounted for $16.7 \%$ of the lymphocyte pool. This patient was treated with an 8 week course of cyclophosphamide at $1.5 \mathrm{mg} / \mathrm{kg}$, a rapid prednisone taper, and two doses of rituximab $1000 \mathrm{mg}$ IV separated by 2 weeks. The patient was back in complete by remission by 6 months.
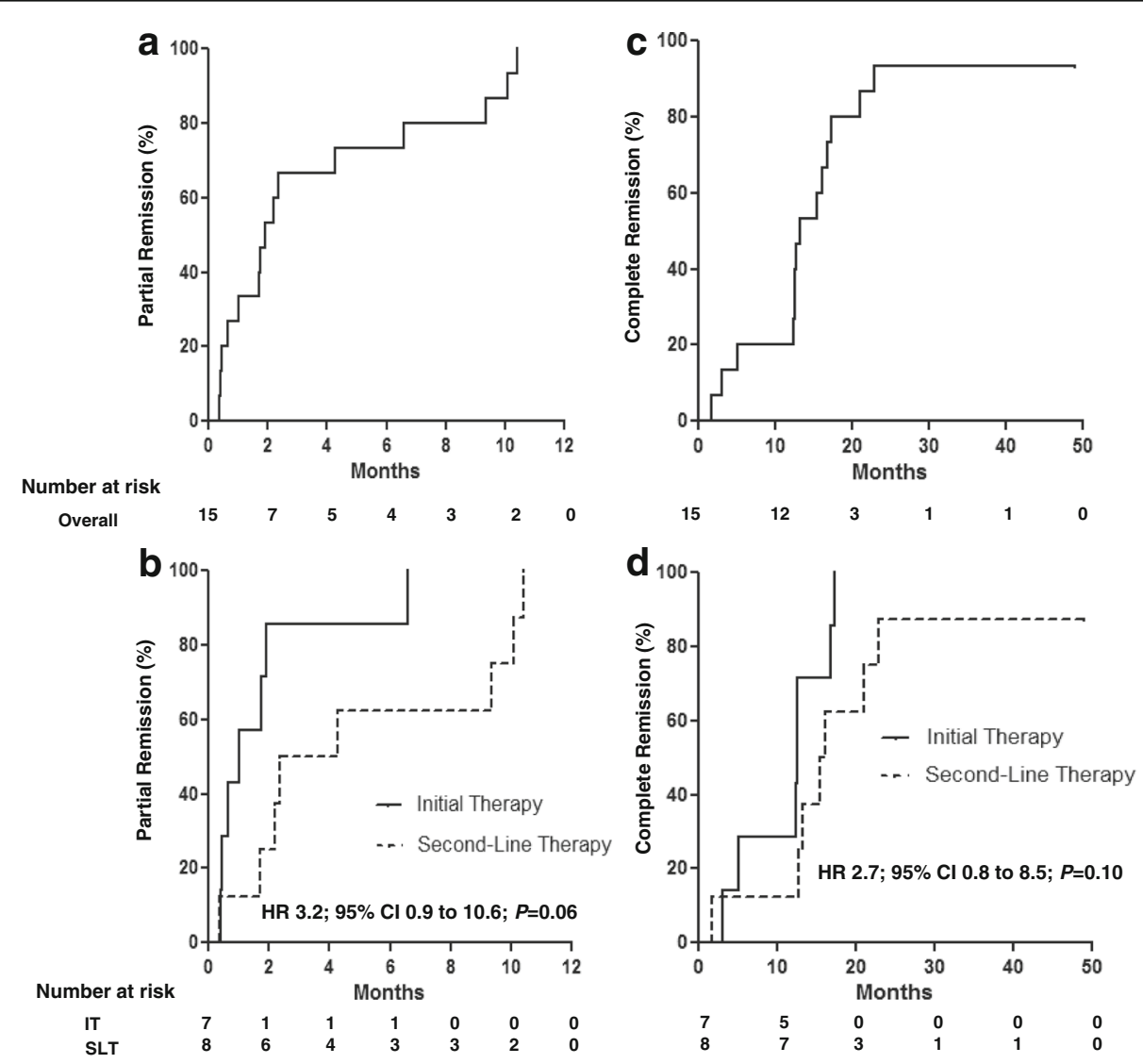

Fig. 2 Kaplan-Meier curves for partial and complete remission. Kaplan-Meier curves for the overall group and stratified by treatment status are shown for partial remission (panels $\mathbf{a}$ and $\mathbf{b}$ ) and complete remission (panels $\mathbf{c}$ and $\mathbf{d}$ ). Abbreviations: HR, hazard ratio; IT, initial therapy; SLT, second-line therapy 


\section{Secondary outcomes}

Response to treatment with RCP at 1 year, both overall and stratified by treatment status, is shown in Table 3 . UPCR fell from a median of 8.2 (IQR, 6.6-11.1) to 0.3 (IQR, 0.2-0.7) g/g $(P<0.001$, Fig. 3).

Overall, there was no change in serum creatinine at 1 year. However, in patients receiving $\mathrm{RCP}$ as secondline therapy, there was a significant fall in serum creatinine (1.3 [IQR, 1.2-2.1] to 1.2 [IQR, 1.1 to 1.7$] \mathrm{mg} / \mathrm{dL}$; $P=0.02$ ). There was a significant rise in serum albumin and a significant decline in cholesterol in both treatment groups (Table 3). Despite treatment with rituximab, there was a significant rise in IgG levels (314 [IQR, 199-551] to 730 [IQR, 538-908] mg/dL; $P=0.003$ ) due to a reduction in urinary losses.

Ten patients had at least 1 year of follow-up after completion of the 2-year RCP regimen. There was no difference in UPCR or serum creatinine 1 year after treatment completion compared with 1 year after treatment initiation (Table 4).

\section{Serious adverse events}

Over a combined follow-up time of 51 patient years, three serious adverse events (SAE) s occurred. Two SAEs, an episode of late-onset neutropenia and a febrile viral syndrome, were felt to be potentially treatment-related. Both events occurred in patients receiving RCP as second-line therapy. The episode of late-onset neutropenia occurred 3.7 months after the patient's $6^{\text {th }}$ rituximab dose and promptly responded to treatment with filgrastim. The patient subsequently received two additional doses of rituximab without incident. The patient with a viral syndrome was hospitalized for evaluation of fever and malaise. An infectious workup, including blood and urine cultures, was negative and the symptoms resolved with only supportive care. A specific virus was not isolated, but the course was most consistent with a viral process.

The third SAE was an episode of altered mental status that occurred after the initiation of high-dose gabapentin.
The patient's mental status returned to baseline following withdrawal of gabapentin, and this SAE was not felt to be a consequence of $\mathrm{MN}$ or the RCP regimen. No patients died or progressed to ESKD.

\section{Discussion}

Treatment with RCP was effective at inducing remission in patients with idiopathic MN. In patients treated for at least 1 year, 100\% achieved partial remission and 93\% achieved complete remission. The response was durable, with only 1 patient sustaining a relapse after completion of treatment. Furthermore, achieving complete remission appears to be time-dependent, with most individuals achieving complete remission greater than 1 year after initiating therapy. However, treatment with a standard regimen of an alkylating agent and glucocorticoids generally achieves complete remission in less than $35 \%$ of patients, even after extended follow up [3, 7, 9]. Similarly, in a report of 100 patients with MN treated with rituximab monotherapy, complete remission occurred in fewer than $30 \%$ of patients [14].

Despite the limited sample size, our results suggest that rates of remission achieved with RCP may be superior to other treatment regimens that have been reported. We attribute the success of the regimen to a multitargeted approach to halt the production of pathogenic antibodies causing MN. Specifically, prednisone and cyclophosphamide target plasmablasts and plasma cells, while rituximab depletes the $B$ cell pool required to replete the plasma cell population. By administering rituximab every 4 months, B cells are prevented from reconstituting. Standard cytotoxic regimens for MN can be circumvented if plasmablasts and plasma cells producing pathogenic antibody are restored from the B cell population. Likewise, rituximab monotherapy is unlikely to be effective if long-lived plasma cells are participating in the disease process.

We hypothesize that the long duration of B cell depletion with RCP will lead to a more sustained remission

Table 3 Response to treatment at 1 year

\begin{tabular}{|c|c|c|c|c|c|c|c|c|c|}
\hline \multirow[b]{2}{*}{ Variable } & \multicolumn{3}{|l|}{ Overall $(n=15)$} & \multicolumn{3}{|c|}{ Initial therapy $(n=7)$} & \multicolumn{3}{|c|}{ Second-line therapy $(n=8)$} \\
\hline & Baseline & 1-Year & $P$ value & Baseline & 1-Year & $P$ value & Baseline & 1-Year & $P$ value \\
\hline UPCR (g/g) & $8.2(6.6-11.1)$ & $0.3(0.2-0.7)$ & $<0.001$ & $6.9(5.2-10.2)$ & $0.2(0.1-0.5)$ & 0.02 & $10.1(8-11.7)$ & $0.6(0.3-0.7)$ & 0.01 \\
\hline Creatinine $(\mathrm{mg} / \mathrm{dL})$ & $1.2(0.8-1.5)$ & $1.0(0.8-1.2)$ & 0.44 & $0.8(0.5-0.9)$ & $0.8(0.7-1.0)$ & 0.13 & $1.3(1.2-2.1)$ & $1.2(1.1-1.7)$ & 0.02 \\
\hline Albumin (mg/dL) & $2.7(2.5-2.8)$ & $4.2(4-4.4)$ & $<0.001$ & $2.7(2.5-2.8)$ & $4.2(3.9-4.4)$ & 0.02 & $2.6(2.4-3.1)$ & $4.2(4.0-4.4)$ & 0.01 \\
\hline Cholesterol $(\mathrm{mg} / \mathrm{dL})^{\mathrm{a}}$ & $350(252-371)$ & $189(148-220)$ & 0.001 & $341(252-367)$ & $167(128-191)$ & 0.02 & $371(249-438)$ & $207(155-251)$ & 0.02 \\
\hline Triglycerides (mg/dL) & $172(122-270)$ & $189(148-220)$ & 0.40 & $134(77-192)$ & $105(80-244)$ & 0.74 & $177(155-546)$ & $182(152-204)$ & 0.24 \\
\hline $\lg G(\mathrm{mg} / \mathrm{dL})^{\mathrm{b}}$ & $314(199-551)$ & $730(538-908)$ & 0.003 & $499(296-731)$ & $806(676-1027)$ & 0.02 & $199(198-308)$ & $611(364-676)$ & 0.08 \\
\hline
\end{tabular}

Data are presented as median (interquartile range). Baseline and 1 year values compared with Wilcoxon signed-rank test

${ }^{\mathrm{a}} 1$ patient in the second-line therapy group did not have baseline cholesterol or triglycerides

b three patients in the second-line therapy group had missing baseline lgG

Abbreviations: IgG immunoglobulin G, UPCR urinary protein:creatinine ratio 

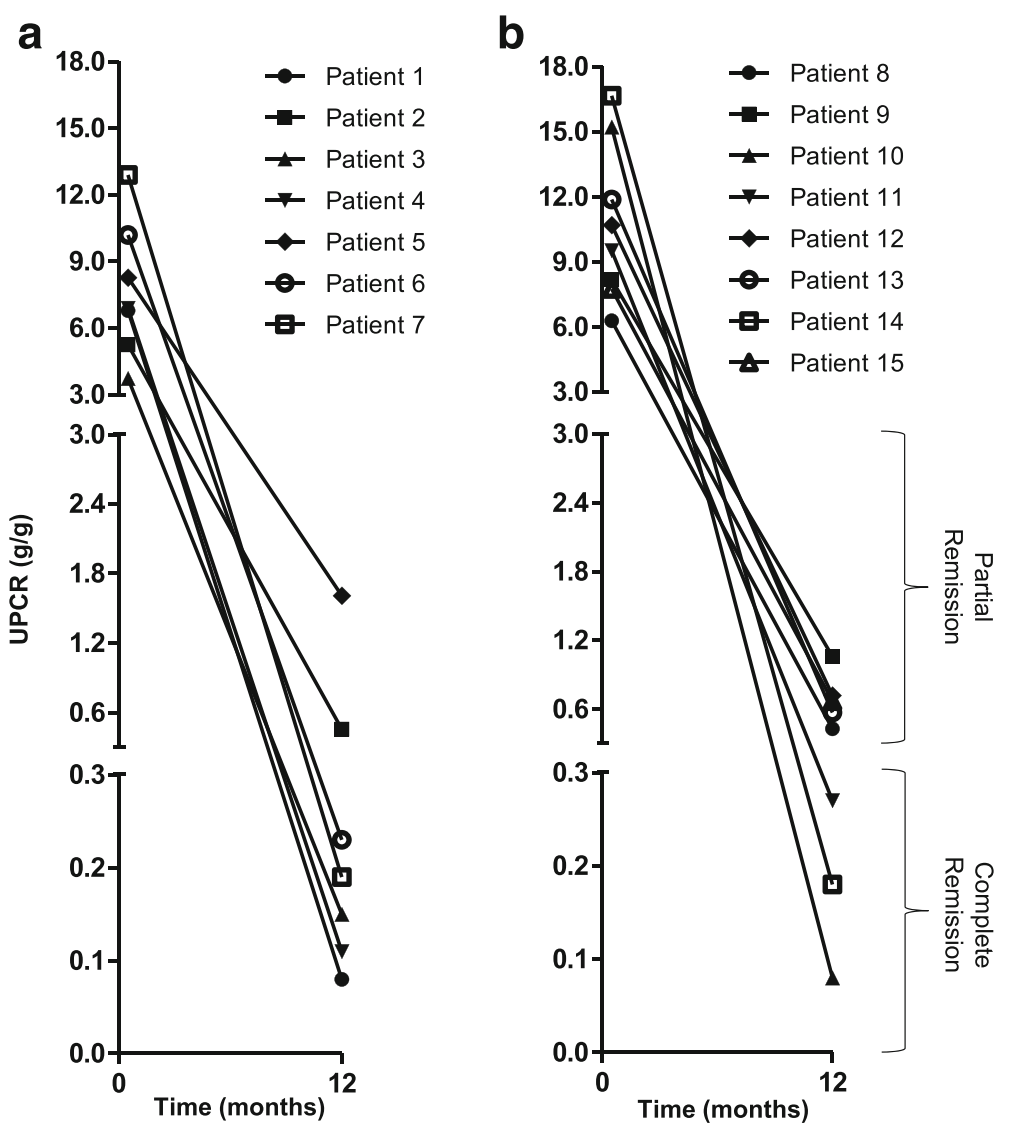

Fig. 3 Change in proteinuria after 1 year of treatment. Data are depicted for patients receiving RCP as initial therapy (panel a) or as second-line therapy (panel b). Abbreviations: UPCR, urinary protein:creatinine ratio

compared with alternative regimens. Following completion of the RCP regimen, 1 relapse occurred over 20 patient-years in a population enriched in patients with relapsing and refractory disease. Prior studies using cytotoxic therapy with prednisone have resulted in relapse rates of approximately $30 \%$ by 1.5 years, and the relapse rate approaches $45 \%$ for calcineurin inhibitor-based regimens $[7,8]$. More data and longer follow-up are needed to more accurately define the relapse rate associated with RCP. The optimal treatment regimen for patients with relapsing disease following RCP is unknown. The

Table 4 Response to treatment at 3 years

\begin{tabular}{llll}
\hline Variable & $\begin{array}{l}\text { 1 year after RCP } \\
\text { initiation }(n=10)\end{array}$ & $\begin{array}{l}1 \text { year after RCP } \\
\text { completion }(n=10)\end{array}$ & $P$ value \\
\hline UPCR $(\mathrm{g} / \mathrm{g})$ & $0.3(0.2-0.7)$ & $0.1(0.1-0.2)$ & 0.09 \\
Albumin $(\mathrm{mg} / \mathrm{dL})$ & $4.2(4.0-4.4)$ & $4.6(4.3-4.7)$ & 0.036 \\
Creatinine $(\mathrm{mg} / \mathrm{dL})$ & $1.0(0.8-1.2)$ & $1.1(0.8-1.3)$ & 0.11 \\
\hline
\end{tabular}

Data are presented as median (interquartile range) for the 10 patients with 1 year of treatment-free follow-up. Values 1 year after RCP initiation were compared to values 1 year after RCP completion with the Wilcoxon signed-rank test

Abbreviations: UPCR urinary protein:creatinine ratio, $R C P$ rituximab, cyclophosphamide, prednisone one patient who sustained a relapse after a treatmentfree interval of 4.8 years was successfully retreated with the RCP regimen. It is possible that early and non-severe relapses may respond well to rituximab alone.

The high rate of complete remission in patients treated with RCP is likely to lead to long-term clinical benefit. Patients attaining complete remission have an excellent renal prognosis and a significantly lower rate of reaching ESKD than those who achieve only partial remission [17, 18]. In one analysis of $348 \mathrm{MN}$ patients with a median follow-up time of 6 years, none of the 102 patients with complete remission progressed to stage V CKD, whereas 9\% of the 132 patients with partial remission progressed to stage V CKD [17]. Likewise, the slope of renal decline was significantly flatter in patients who achieved complete remission [17]. Additionally, since albuminuria is a strong independent risk factor for coronary artery disease and stroke, maximizing the reduction of proteinuria in patients with $\mathrm{MN}$ with $\mathrm{RCP}$ may have important extra-renal benefits as well [19].

There may be concern that the simultaneous use of 3 immunosuppressive medications will lead to an increased risk of infectious complications and other 
adverse events. In our study, three serious adverse events occurred over 51 patient years. This regimen allows for a rapid prednisone taper in which patients are reduced to a dose of $15 \mathrm{mg}$ per day by 4 weeks. Moreover, the cumulative dose of cyclophosphamide used in this regimen $(97 \mathrm{mg} / \mathrm{kg}$ prior to renal adjustment) is significantly less than in other regimens for MN. For example, in the Ponticelli regimen, patients receive a total of $180 \mathrm{mg} / \mathrm{kg}$ of cyclophosphamide. Adjustment of the cyclophosphamide dose for renal function likely serves to further mitigate potential side effects. The risk of urothelial carcinoma is dose-dependent, and is unlikely to occur with the doses used in our regimen [20, 21]. Cyclophosphamide has also been associated with the development of myelodysplastic syndrome, leukemia, and other malignancies in a dose-dependent fashion [22, 23] . However, cyclophosphamide in the RCP regimen is used for a shorter duration and at a lower dose than conventional regimens used for the treatment of renal or rheumatologic diseases. Thus, while it is difficult to estimate the exact risk of malignancy with RCP, it is likely lower than the incidence associated with other cyclophosphamidebased regimens.

Rituximab in our protocol was dosed every 4 months for 2 years with the aim of maintaining continuous B cell depletion. This represents a longer duration of therapy than other regimens using rituximab for idiopathic MN [12-14, 24]. Our rationale was that more prolonged therapy would lead to a higher rate of complete remission and lead to lower rates of relapse without a significant increase in adverse events. Indeed, achieving complete remission appeared to be time-dependent, with most individuals achieving complete remission greater than 1 year after initiating therapy. Moreover, the response appeared durable with only 1 patient sustaining a relapse after complete remission was attained. A prior investigation of 173 patients with ANCA vasculitis demonstrated that rituximab-induced continuous B cell depletion for a median duration of 2.1 years was safe and effective with survival that mirrored that of the general population [25]. While the RCP regimen was well tolerated during the observation-period, we cannot exclude the possibility of treatment-related side effects developing in the future.

Our study has several important limitations. Patient selection in studies of $\mathrm{MN}$ is important to consider given the possibility of spontaneous remission in low-risk patients [2]. Inclusion of patients with a higher probability of spontaneous remission can result in overestimation of treatment efficacy. Of note, our study population was enriched in women compared to the male predominance typically observed in MN. There is evidence that female patients may have a better prognosis and a higher rate of spontaneous remission [26, 27]. In addition, some patients receiving $\mathrm{RCP}$ as initial therapy were treated early in their disease course due to debilitating nephrosis, and we cannot exclude the possibility that a subset would have remitted spontaneously. However, $50 \%$ of the patients in our study had relapsing or refractory disease, and the high-grade baseline proteinuria (median UPRC of $8.2 \mathrm{~g} / \mathrm{g}$ ) decreases the probability of spontaneous remission [28]. Moreover, the rate of spontaneous complete remission in idiopathic $\mathrm{MN}$ is low. In an observational study of $100 \mathrm{pa}-$ tients with predominantly low-risk disease, only approximately $10 \%$ of patients achieved complete remission by 2 years [29]. Thus, it is unlikely that the high rates of remission that we observed with RCP can be attributed to spontaneous remissions.

The discovery of antibodies to PLA2R as the inciting event in the majority of cases of idiopathic $\mathrm{MN}$ has greatly advanced the mechanistic understanding of the disease [11]. In addition, a decline in anti-PLA2R antibodies following treatment with rituximab predicts, and typically precedes, clinical response [30]. Although treatment with RCP led to undetectable PLA2R antibodies in the three patients with documented baseline circulating antibodies, our limited data precluded a robust analysis of clinical response with a change in antibody titers.

An additional limitation is that a spot UPCR, rather than a 24-h urine collection, was used to quantify proteinuria. This study is a retrospective analysis of patients undergoing routine clinical care, a setting in which the 24-h urine collection is cumbersome and often collected inappropriately. The UPCR has excellent correlation with 24-h urine collection [31]. However, the UPCR is subject to more intraperson variability and is influenced by the rate of urinary creatinine excretion [32]. Nonetheless, all patients who achieved complete remission had multiple subsequent UPCR values of $<0.3 \mathrm{~g} / \mathrm{g}$ after attaining complete remission. Given the repeated confirmation of complete remission in our patients, it is unlikely that the variability of the UPCR significantly influenced the results.

Finally, the study is single-center, of limited size, and lacks a comparator group. Statistical results must be interpreted with caution in this setting. Larger studies are required to confirm our findings.

\section{Conclusions}

In summary, RCP was effective and safe for the treatment of idiopathic $\mathrm{MN}$ and may allow for a remission rate superior to existing regimens. Over a median follow-up time of 37 months, $100 \%$ of patients achieved partial remission and $93 \%$ of patients achieved complete remission. In addition, outcomes were similar regardless of incident or relapsing disease. Larger studies comparing RCP to established treatments are needed to further assess the utility of this regimen in the treatment of idiopathic $\mathrm{MN}$. 


\section{Additional file}

Additional file 1: Figure S1. Change in proteinuria with treatment. Data are depicted for patients receiving RCP as initial therapy (panel A) or as second-line therapy (panel B). One patient (Patient 9 in panel B) did not achieve complete remission. After achieving complete remission, all patients had a subsequent urinary protein:creatinine ratio $<0.3 \mathrm{~g} / \mathrm{g}$. Abbreviations: UPCR, urinary protein:creatinine ratio. (DOCX 55 kb)

\section{Abbreviations}

ACE-I: Angiotensin converting enzyme inhibitor; ARB: Angiotensin receptor blocker; eGFR: Estimated glomerular filtration rate; ESKD: End-stage kidney disease; MN: Membranous nephropathy; PLA2R: Phospholipase A2 receptor; RCP: Combination rituximab, low-dose oral cyclophosphamide, and accelerated prednisone taper; UPCR: Urinary protein to creatinine ratio

\section{Acknowledgements}

The authors wish to thank the clinic personnel dedicated to the care of the patients in the MGH Vasculitis and Glomerulonephritis Clinic, including Donna Hagstrom, Kate Cosgrove and Luke Cogswell. We are also indebted to the MGH Vasculitis and Glomerulonephritis Center's clinical research coordinator, Andy Murphy.

\section{Funding}

FBC is supported by National Institutes of Health grant 5T32DK007540 and a fellowship grant from Genentech (G-17505).

WFP3 is supported by grants P01-DK058335, 1UM1-DK100845, and F32DK097891 from the National Institute of Diabetes and Digestive Kidney Diseases (NIDDK) and receives translational research funding from The Broad Institute.

DEL is supported by grant K23DK106448 from the NIDDK.

The funding agencies had no role in carrying out the study.

\section{Availability of data and materials}

The de-identified raw data used for this analysis is provided in an attached spreadsheet.

\section{Authors' contributions}

Research idea and study design: FBC, DEL WFP, CTO, KL, JLN; Data acquisition: KL, FBC, DEL; Data analysis/interpretation: FBC, DEL, WFP, JLN; Statistical analysis: FBC, DEL; Supervision or mentorship: JLN. Each author made important contributions to the manuscript and accepts accountability for its accuracy. JLN takes responsibility that the results have been reported honestly, accurately, and transparently. All authors read and approved the final manuscript.

\section{Competing interests}

JLN has served as a rituximab-specific advisory board member for Genentech and is currently participating in the Genentech-sponsored Rituximab in ANCA-Associated Vasculitis Registry (RAVER) Study.

FBC is partially supported by a fellowship grant from Genentech (G-17505).

\section{Consent for publication}

Not applicable.

\section{Ethics approval and consent to participate}

We performed a retrospective analysis of patients undergoing routine care at the Massachusetts General Hospital Vasculitis and Glomerulonephritis Center. The study was approved by the Massachusetts General Hospital Institutional Review Board.

\section{Author details}

${ }^{1}$ Vasculitis and Glomerulonephritis Center, Division of Nephrology, Massachusetts General Hospital, 101 Merrimac St, Boston 02114, MA, USA. 2Division of Renal Medicine, Brigham and Women's Hospital, Boston, MA, USA. ${ }^{3}$ Division of Nephrology, Baylor University Medical Center at Dallas, Dallas, TX, USA. ${ }^{4}$ Division of Nephrology and Hypertension, Department of Medicine, University of North Carolina Kidney Center, Chapel Hill, NC, USA.

Received: 22 March 2016 Accepted: 23 January 2017

Published online: 01 February 2017

\section{References}

1. Rivera F, Lopez-Gomez JM, Perez-Garcia R. Spanish registry of glomerulonephritis: clinicopathologic correlations of renal pathology in Spain. Kidney Int. 2004;66(3):898-904.

2. Ponticelli C, Glassock RJ. Glomerular diseases: membranous nephropathy-a modern view. Clin J Am Soc Nephrol. 2014;9(3):609-16.

3. Ponticelli C, Zucchelli P, Passerini P, Cesana B, Locatelli F, Pasquali S, Sasdelli M, Redaelli B, Grassi C, Pozzi C. A 10-year follow-up of a randomized study with methylprednisolone and chlorambucil in membranous nephropathy. Kidney Int. 1995;48(5):1600-4.

4. Jha V, Ganguli A, Saha TK, Kohli HS, Sud K, Gupta KL, Joshi K, Sakhuja V. A randomized, controlled trial of steroids and cyclophosphamide in adults with nephrotic syndrome caused by idiopathic membranous nephropathy. J Am Soc Nephrol. 2007;18(6):1899-904.

5. Cattran DC, Pei Y, Greenwood C. Predicting progression in membranous glomerulonephritis. Nephrol Dial Transplant. 1992;7 Suppl 1:48-52.

6. Anonymous Kidney Disease: Improving Global Outcomes (KDIGO) Glomerulonephritis Work Group. KDIGO clinical practice guideline for glomerulonephritis. Kidney Int. 2012;2:139-274.

7. Ponticelli C, Altieri P, Scolari F, Passerini P, Roccatello D, Cesana B, Melis P, Valzorio B, Sasdelli M, Pasquali S, Pozzi C, Piccoli G, Lupo A, Segagni S, Antonucci F, Dugo M, Minari M, Scalia A, Pedrini L, Pisano G, Grassi C, Farina M, Bellazzi R. A randomized study comparing methylprednisolone plus chlorambucil versus methylprednisolone plus cyclophosphamide in idiopathic membranous nephropathy. J Am Soc Nephrol. 1998;9(3):444-50.

8. Cattran DC, Appel GB, Hebert LA, Hunsicker LG, Pohl MA, Hoy WE, Maxwell DR, Kunis CL, North America Nephrotic Syndrome Study Group. Cyclosporine in patients with steroid-resistant membranous nephropathy: a randomized trial. Kidney Int. 2001;59(4):1484-90.

9. Fervenza FC, Sethi S, Specks U. Idiopathic membranous nephropathy: diagnosis and treatment. Clin J Am Soc Nephrol. 2008;3(3):905-19.

10. Praga M, Barrio V, Juarez GF, Luno J, Grupo Espanol de Estudio de la Nefropatia Membranosa. Tacrolimus monotherapy in membranous nephropathy: a randomized controlled trial. Kidney Int. 2007;71(9):924-30.

11. Beck Jr LH, Bonegio RG, Lambeau G, Beck DM, Powell DW, Cummins TD, Klein JB, Salant DJ. M-type phospholipase A2 receptor as target antigen in idiopathic membranous nephropathy. N Engl J Med. 2009;361(1):11-21.

12. Fervenza FC, Cosio FG, Erickson SB, Specks U, Herzenberg AM, Dillon JJ, Leung N, Cohen IM, Wochos DN, Bergstralh E, Hladunewich M, Cattran DC. Rituximab treatment of idiopathic membranous nephropathy. Kidney Int. 2008;73(1):117-25.

13. Fervenza FC, Abraham RS, Erickson SB, Irazabal MV, Eirin A, Specks U, Nachman PH, Bergstralh EJ, Leung N, Cosio FG, Hogan MC, Dillon JJ, Hickson LJ, Li X, Cattran DC, Mayo Nephrology Collaborative Group. Rituximab therapy in idiopathic membranous nephropathy: a 2-year study. Clin J Am Soc Nephrol. 2010;5(12):2188-98.

14. Ruggenenti P, Cravedi P, Chianca A, Perna A, Ruggiero B, Gaspari F, Rambaldi A, Marasa M, Remuzzi G. Rituximab in idiopathic membranous nephropathy. J Am Soc Nephrol. 2012;23(8):1416-25.

15. Levey AS, Stevens LA, Schmid CH, Zhang YL, Castro 3rd AF, Feldman HI, Kusek JW, Eggers P, Van Lente F, Greene T, Coresh J, CKD-EPI (Chronic Kidney Disease Epidemiology Collaboration). A new equation to estimate glomerular filtration rate. Ann Intern Med. 2009;150(9):604-12.

16. Breedveld F, Agarwal S, Yin M, Ren S, Li NF, Shaw TM, Davies BE. Rituximab pharmacokinetics in patients with rheumatoid arthritis: B-cell levels do not correlate with clinical response. J Clin Pharmacol. 2007;47(9):1119-28.

17. Troyanov S, Wall CA, Miller JA, Scholey JW, Cattran DC, Toronto Glomerulonephritis Registry Group. Idiopathic membranous nephropathy: definition and relevance of a partial remission. Kidney Int. 2004;66(3):1199-205.

18. Laluck Jr BJ, Cattran DC. Prognosis after a complete remission in adult patients with idiopathic membranous nephropathy. Am J Kidney Dis. 1999;33(6):1026-32.

19. Perkovic V, Verdon C, Ninomiya T, Barzi F, Cass A, Patel A, Jardine M, Gallagher M, Turnbull F, Chalmers J, Craig J, Huxley R. The relationship between proteinuria and coronary risk: a systematic review and meta-analysis. Plos Med. 2008;5(10):e207.

20. Talar-Williams C, Hijazi YM, Walther MM, Linehan WM, Hallahan CW, Lubensky I, Kerr GS, Hoffman GS, Fauci AS, Sneller MC. Cyclophosphamideinduced cystitis and bladder cancer in patients with Wegener granulomatosis. Ann Intern Med. 1996;124(5):477-84.

21. Travis LB, Curtis RE, Glimelius B, Holowaty EJ, Van Leeuwen FE, Lynch CF, Hagenbeek A, Stovall M, Banks PM, Adami J. Bladder and kidney cancer 
following cyclophosphamide therapy for non-Hodgkin's lymphoma. J Natl Cancer Inst. 1995;87(7):524-30.

22. Reinhold-Keller E, Beuge N, Latza U, de Groot K, Rudert H, Nolle B, Heller M, Gross WL. An interdisciplinary approach to the care of patients with Wegener's granulomatosis: long-term outcome in 155 patients. Arthritis Rheum. 2000:43(5):1021-32.

23. van den Brand JA, van Dijk PR, Hofstra JM, Wetzels JF. Cancer risk after cyclophosphamide treatment in idiopathic membranous nephropathy. Clin J Am Soc Nephrol. 2014;9(6):1066-73.

24. Bomback AS, Derebail VK, McGregor JG, Kshirsagar AV, Falk RJ, Nachman PH. Rituximab therapy for membranous nephropathy: a systematic review. Clin J Am Soc Nephrol. 2009;4(4):734-44.

25. Pendergraft 3rd WF, Cortazar FB, Wenger J, Murphy AP, Rhee EP, Laliberte KA Niles JL. Long-term maintenance therapy using rituximab-induced continuous B-cell depletion in patients with ANCA vasculitis. Clin J Am Soc Nephrol. 2014;9(4):736-44.

26. Cattran DC, Reich HN, Beanlands HJ, Miller JA, Scholey JW, Troyanov S Genes, Gender and Glomerulonephritis Group. The impact of sex in primary glomerulonephritis. Nephrol Dial Transplant. 2008;23(7):2247-53.

27. Shiiki H, Saito T, Nishitani Y, Mitarai T, Yorioka N, Yoshimura A, Yokoyama H, Nishi S, Tomino Y, Kurokawa K, Sakai H, Research Group on Progressive Renal Diseases in Japan. Prognosis and risk factors for idiopathic membranous nephropathy with nephrotic syndrome in Japan. Kidney Int. 2004;65(4):1400-7.

28. Polanco N, Gutierrez E, Covarsi A, Ariza F, Carreno A, Vigil A, Baltar J, Fernandez-Fresnedo G, Martin C, Pons S, Lorenzo D, Bernis C, Arrizabalaga P, Fernandez-Juarez G, Barrio V, Sierra M, Castellanos I, Espinosa M, Rivera F. Oliet A, Fernandez-Vega F, Praga M, Grupo de Estudio de las Enfermedades Glomerulares de la Sociedad Espanola de Nefrologia. Spontaneous remission of nephrotic syndrome in idiopathic membranous nephropathy. J Am Soc Nephrol. 2010;21(4):697-704.

29. Schieppati A, Mosconi L, Perna A, Mecca G, Bertani T, Garattini S, Remuzzi G. Prognosis of untreated patients with idiopathic membranous nephropathy. N Engl J Med. 1993;329(2):85-9.

30. Beck Jr LH, Fervenza FC, Beck DM, Bonegio RG, Malik FA, Erickson SB, Cosio FG, Cattran DC, Salant DJ. Rituximab-induced depletion of anti-PLA2R autoantibodies predicts response in membranous nephropathy. J Am Soc Nephrol. 2011;22(8):1543-50

31. Ginsberg JM, Chang BS, Matarese RA, Garella S. Use of single voided urine samples to estimate quantitative proteinuria. N Engl J Med. 1983:309(25):1543-6.

32. Naresh CN, Hayen A, Craig JC, Chadban SJ. Day-to-day variability in spot urine protein-creatinine ratio measurements. Am J Kidney Dis. 2012;60(4):561-6.

\section{Submit your next manuscript to BioMed Central and we will help you at every step:}

- We accept pre-submission inquiries

- Our selector tool helps you to find the most relevant journal

- We provide round the clock customer support

- Convenient online submission

- Thorough peer review

- Inclusion in PubMed and all major indexing services

- Maximum visibility for your research

Submit your manuscript at www.biomedcentral.com/submit

) Biomed Central 